\title{
Adaptation of water resource systems to an uncertain future
}

\author{
Claire L. Walsh ${ }^{1}$, Stephen Blenkinsop ${ }^{1}$, Hayley J. Fowler ${ }^{1}$, Aidan Burton ${ }^{1}$, Richard J. Dawson ${ }^{1}$, Vassilis Glenis ${ }^{1}$, \\ Lucy J. Manning ${ }^{\mathrm{a}}$, Golnaz Jahanshahi ${ }^{1}$, and Chris G. Kilsby ${ }^{1}$ \\ ${ }^{1}$ Centre for Earth Systems Engineering Research, School of Civil Engineering and Geosciences, Newcastle University, \\ Newcastle upon Tyne, UK \\ a formerly at: Centre for Earth Systems Engineering Research, School of Civil Engineering and Geosciences, \\ Newcastle University, Newcastle upon Tyne, UK
}

Correspondence to: Claire L. Walsh (claire.walsh@newcastle.ac.uk)

Received: 28 July 2015 - Published in Hydrol. Earth Syst. Sci. Discuss.: 2 September 2015

Revised: 20 April 2016 - Accepted: 30 April 2016 - Published: 12 May 2016

\begin{abstract}
Globally, water resources management faces significant challenges from changing climate and growing populations. At local scales, the information provided by climate models is insufficient to support the water sector in making future adaptation decisions. Furthermore, projections of change in local water resources are wrought with uncertainties surrounding natural variability, future greenhouse gas emissions, model structure, population growth, and water consumption habits. To analyse the magnitude of these uncertainties, and their implications for local-scale water resource planning, we present a top-down approach for testing climate change adaptation options using probabilistic climate scenarios and demand projections. An integrated modelling framework is developed which implements a new, gridded spatial weather generator, coupled with a rainfallrunoff model and water resource management simulation model. We use this to provide projections of the number of days and associated uncertainty that will require implementation of demand saving measures such as hose pipe bans and drought orders. Results, which are demonstrated for the Thames Basin, UK, indicate existing water supplies are sensitive to a changing climate and an increasing population, and that the frequency of severe demand saving measures are projected to increase. Considering both climate projections and population growth, the median number of drought order occurrences may increase 5 -fold by the 2050s. The effectiveness of a range of demand management and supply options have been tested and shown to provide significant benefits in terms of reducing the number of demand saving days. A decrease in per capita demand of $3.75 \%$ reduces the median frequency of drought order measures by $50 \%$ by the
\end{abstract}

2020s. We found that increased supply arising from various adaptation options may compensate for increasingly variable flows; however, without reductions in overall demand for water resources such options will be insufficient on their own to adapt to uncertainties in the projected changes in climate and population. For example, a $30 \%$ reduction in overall demand by 2050 has a greater impact on reducing the frequency of drought orders than any of the individual or combinations of supply options; hence, a portfolio of measures is required.

\section{Introduction}

Climate change projections point to longer or more frequent (or both) meteorological droughts in some regions by 2100 but there remain substantial uncertainties as to how rainfall and soil moisture deficits might translate into prolonged periods of reduced streamflow and groundwater levels (IPCC, 2014). This and other pressures affect and will continue to affect UK water availability into the future. Climate change could cause a decline in the amount of water available for supply, particularly in summer months if lower average rainfall coincides with increased temperatures (e.g. Murphy et al., 2009). Water demand may also be sensitive to climate variability, although few studies have examined this aspect (e.g. Parker and Wilby, 2013). Population growth, alongside a greater number of single-occupancy households will greatly affect water demand, and this stresses the need for greater water efficiency. Water resources may therefore increasingly need to be enhanced and managed through new supply or demand management options. Supply options may 
include storage reservoirs, inter-basin transfers, desalination plants, effluent reuse, and groundwater and river abstractions whilst demand management options may include water meters, water saving devices, efficient appliances, rainwater collection systems, and grey water recycling.

A number of studies have investigated the impact of climate change on water resources, addressing the associated uncertainties, using both deterministic and probabilistic projections of climate change. For example, in the UK these include Wilby and Harris (2006), New et al. (2007), Dessai and Hulme (2007), Christensen and Lettenmaier (2007), Vidal and Wade (2009), Manning et al. (2009), and Lopez et al. (2009). Burke and Brown (2010) indicated that an 11 member HadRM3 perturbed physics ensemble showed uncertainty as to whether drought occurrence will decrease or increase across the UK by the end of the 21 st century (consistent with earlier results from a multi-model ensemble; Blenkinsop and Fowler, 2007) although they identify a predominant tendency to the latter. Burke and Brown (2010) demonstrate similar results, with relatively little spatial variation across the UK. Such studies show the sensitivity of projections to climate model structure and parameterization and suggest that methods to downscale climate information can result in large sources of uncertainty in future river flows. However, a "cascade" of uncertainties arise when considering climate change impact assessments for decision making (Jones, 2000). Wilby (2005) showed that uncertainties associated with impact studies arise from model structure, choice of model calibration period, choice of parameter sets, as well as climate scenarios and downscaling methods.

In this study, we use the UK Climate Projections (UKCP09) which provides an ensemble of climate model outputs that capture a number of important uncertainties in climate model parameterization and structure (Murphy et al., 2009). The UKCP09 outputs have been used to consider: flood risk (Cloke et al., 2013; Kay and Jones, 2012), changes in precipitation and potential evapotranspiration (PET) in upland river catchments (Thompson, 2012), sediment yield in catchments (Coulthard et al., 2012), urban heat island effects (Lee and Levermore, 2013), and overheating in buildings (Patidar et al., 2014; Jenkins et al., 2014). Their release and availability has also enabled better assessment of uncertainties in projections of water availability in a changing climate (e.g. Christierson et al., 2012; Harris et al., 2013; Warren and Holman, 2012). Using the UKCP09 projections, Harris et al. (2013) found that for the North Staffordshire Water Resource Zone uncertainty in climate model parameterization causes a greater proportion of uncertainty in estimates for the 2080s of change in overall flow and water shortage per year than emission scenario choice. Whitehead et al. (2006), Wilby and Harris (2006), Dessai and Hulme (2007), and New et al. (2007) have all conducted end-to-end assessments of propagation of uncertainties in adaptation assessments. Understanding the range of uncertainties when assessing future water shortages in the face of climate change will enable policies and strategies to be designed that are robust to the full range of plausible futures. Methods such as robust decision making (RDM) provide a quantitative approach to facilitate decision-making under a range of assumptions and uncertainties. RDM has been used to develop long-range water management plans in the US (Groves et al., 2008; Lempert and Groves, 2010). Matrosov et al. (2013) applied both RDM and info-gap decision theory to consider uncertainties to proposed water supply portfolios for the Thames Basin. Borgomeo et al. (2014) demonstrated a methodology based on UKCP09 that used non-stationary probabilistic climate scenarios to aid risk-based water resource management. More recently the decision-scaling method (Brown et al., 2012) or climate stress testing (Brown and Wilby, 2012) has been applied to water resources systems. Multiple sources of climate information, climate projections, and stochastic assessments are used to evaluate risks (Brown et al., 2012) and subsequently applied to determine robust adaptation strategies (e.g. Whateley et al., 2014; Steinschneider et al., 2015).

This paper builds on and extends this previous research to assess current and future water resources risk by developing and integrating:

- simulation models of precipitation, catchment hydrology, and water resource systems within an uncertainty analysis framework;

- a new spatial weather generator, that unlike previous work in this area, e.g. Borgomeo et al. (2014), captures the spatial variability of rainfall in large catchments to produce high-resolution catchment-wide precipitation simulations for the Thames Basin in the UK;

- consideration of climate uncertainties as a driver of water resource availability, as in e.g. Harris et al. (2013), but also evaluating other uncertainties such as changes in future demand;

- analysis and testing of the effectiveness of a number of adaptation options to manage both the demand and supply of water resources; and,

- provision of end-user relevant water resource indicators increasingly referred to as "climate services" (Hewitt et al., 2012) such as the frequency of triggering reservoir storage control levels, or triggering of demand saving measures, that are used by water companies (e.g. Thames Water, 2014) and promoted by the UK Government (Defra, 2008) and the Environment Agency.

Figure 1 outlines the methodological approach taken and the associated sequence of models used to simulate the Thames Valley water resource system. Starting from the climate model outputs provided by UKCP09, spatially consistent downscaled rainfall scenarios are generated using a spatial rainfall model of the Thames and Lee river basins. 


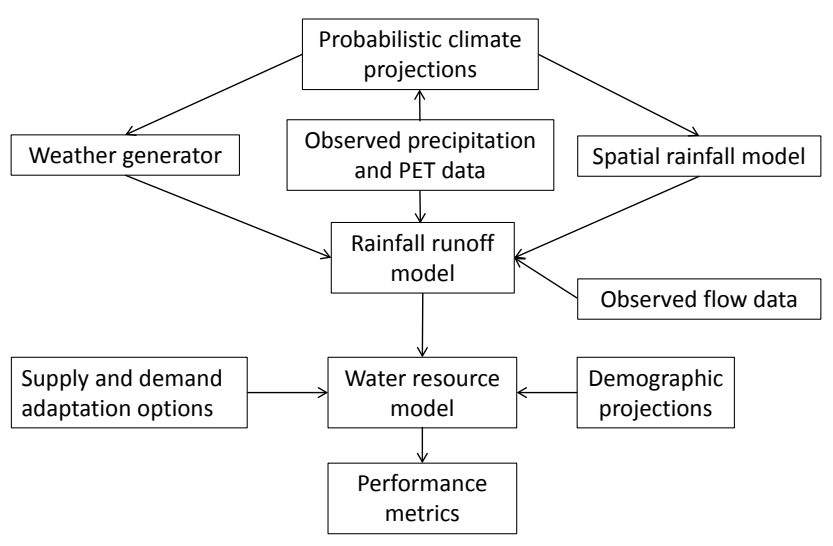

Figure 1. Methodological approach for the study of current and future water resources for the Thames.

These, alongside corresponding downscaled PET data produced with a weather generator, are used to drive catchment rainfall-runoff models, which output corresponding river flows. These, in turn, are input to a model of the water resource system which enables a range of supply and demand management options to be tested which incorporate projections of demographic change.

\section{Methodology}

\subsection{Case study: Thames Basin, UK}

The Thames Basin (Fig. 2) is $10000 \mathrm{~km}^{2}$ in area, mainly underlain by permeable chalk, the basin is predominantly rural, yet densely urbanized downstream. The south-east of England is the most water-scarce region in the UK, having lower than average rainfall and a very large water demand (Environment Agency, 2007a), i.e. "seriously" water stressed. The basin receives an average of $690 \mathrm{~mm}$ of rainfall each year $(250 \mathrm{~mm}$ only is effective rainfall; Environment Agency, 2014) compared to a national average for England and Wales of $897 \mathrm{~mm}$. The River Thames and River Lee supply most of the water for London and south-east England, with $70 \%$ of all water being taken from upstream of Teddington Weir; the remainder is abstracted from aquifers (GLA, 2011). Per capita, Londoners consume more water per day $(167 \mathrm{~L})$ than the UK average $(146 \mathrm{~L})$. Much of the water resource system's infrastructure is more than 150 years old and leakage is a major issue which is currently being addressed. The GLA (2011) expect London's population to rise from 7.56 million at present to between 8.79 and 9.11 million by 2031. UKCP09 probabilistic projections (Murphy et al., 2009) identify potential future climatic pressures in this region (50th percentile figures), suggesting that average summer temperatures could increase by $2.7^{\circ} \mathrm{C}$ and winter temperatures by $2.2^{\circ} \mathrm{C}$. Average summer rainfall is projected to decrease by $18 \%$ and winter rainfall to increase by $15 \%$ (GLA, 2011).

\subsection{Probabilistic climate scenarios}

Uncertainties in projections of future climate originate from a number of sources, including modelling uncertainty. It is not meaningful to use only one model realization in climate change assessments. UKCP09 provides a perturbed physics ensemble (PPE) of simulations, downscaled using the regional climate model (RCM) HadRM3 at a resolution of $25 \mathrm{~km}$ where each ensemble member uses different parameter values within expert-specified bounds. UKCP09 also incorporates projections from 12 other climate models possessing different structures, allowing the sampling of structural modelling errors from a multi-model ensemble. These two ensembles are combined within a Bayesian statistical framework to produce the UKCP09 probabilistic projections (Murphy et al., 2009). Additional downscaling onto a $5 \mathrm{~km}$ grid through a combined change factor (CF) and weather generator approach, provides a spatial resolution more appropriate for considering catchment response.

Here, we use an extended version of UKCP09 stochastic weather generator (Jones et al., 2009) (referred to hereafter as UKCP09-WG), which provides simulations of daily and hourly weather variables for both a baseline (19611990) and a selected future climate (emissions scenario and time horizon) for each member of a probabilistic projection. Projections for two 30-year periods centred on the 2020s (SCN20) and 2050s (SCN50) were identified as most relevant to stakeholders which expressed the greatest need for near- to medium-term future scenarios (Hallett, 2013). The analysis was restricted to the A1B (medium) emissions scenario, although a complete consideration of future uncertainties would need to examine alternative scenarios. These future projections were assessed against the 1961-1990 baseline (BSL) which also served to provide information on current hazard.

The standard UKCP09-WG framework is extended here by replacing the single-site rainfall model with a spatial rainfall model, the stochastic spatial-temporal Neyman-Scott rectangular pulses model (STNSRP; Cowpertwait, 1995; Burton et al., 2008). This models spatial rainfall variability and thus helps to capture non-linear impacts of climate change on water resources - in particular, correlated weather events between sub-basins. Whilst this is not necessary for small catchments (e.g. Harris et al., 2013, use a simple scaling relationship), such an approach is required here due to the larger scale of the Thames Basin. The spatially continuous nature of the STNSRP process is therefore advantageous as it may be sampled at any location (Burton et al., 2010a) or even on a regular grid (e.g. Blanc et al., 2012; Burton et al., 2013). Here, we present one of the first published applications to generate and assess the impact of future climate gridded rainfall data sets using the STNSRP model. 


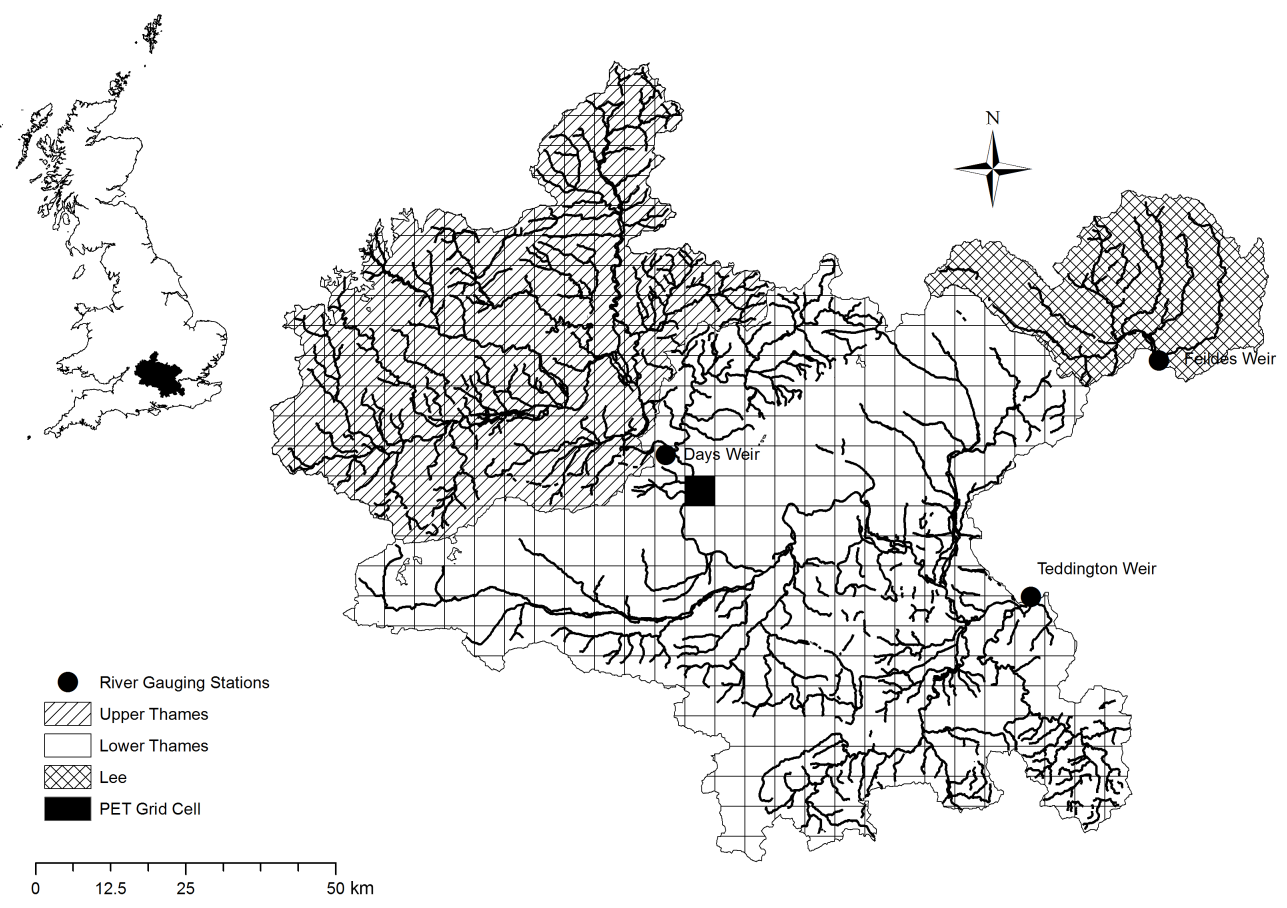

Figure 2. Map of the Thames Basin showing the gauging stations at the outlet of the three sub-basins: Upper Thames, Lower Thames, and Lee. The grid cells correspond to the $5 \mathrm{~km}$ spatially correlated gridded rainfall; the black grid cell indicates the catchment's centroid cell for which PET was generated.

Ten 100-year-long gridded daily rainfall simulations were generated using the BSL climatology (Perry and Hollis, 2005a, b). Following the UKCP09 approach (Jones et al., 2009) 100 sets of monthly change factors for each time slice for the A1B emissions scenario were randomly sampled and applied to the observed daily rainfall statistics. The rainfall model was refitted to these perturbed statistics and used to generate 100-year gridded daily simulations for each of the randomly sampled 100 sets of CFs for both SCN20 and SCN50. Batch processing of these scenarios was facilitated through the use of the efficient STNSRP simulation scheme described in Burton et al. (2010a). The CRU daily weather generator was used to generate long time series of synthetic daily weather variables, conditioned by the synthetic daily rainfall generated with the NSRP process (Kilsby et al., 2007). For simulation, input rainfall series were derived for each sub-catchment from the weather generator output by averaging simulated point rainfall records generated over the $5 \mathrm{~km}$ grid cells covering the sub-catchments. Here, only the PET output variable was required as input to the rainfall-runoff model. Since the region under study concerns only $10000 \mathrm{~km}^{2}$, with a maximum elevation of $330 \mathrm{~m}$, PET is not very variable, so a single PET record has been used for all catchments, representative of the point rainfall record generated at the centroid of the whole Thames Basin. It is recognized that within each of the catchments the variety of land cover uses would in turn affect moisture losses. How- ever, given the similarity of the catchments in terms of elevation and heterogeneity of land cover, and that the rainfallrunoff model is lumped, a single PET record generated at the centroid of the whole Thames Basin was used; the representative $5 \mathrm{~km}$ grid cell is highlighted in Fig. 2. A forthcoming paper will present the application of a spatial weather generator which will feed a physically based, spatially distributed hydrological model which will allow better representation of both the climatological and land cover heterogeneity of the catchment. Furthermore, it will enable changes in land cover, i.e. increasing urban areas to be considered.

Supplementary resources present further details about the validation of the UKCP09-WG and presents a brief assessment of the robustness of the random sample of CFs used in this study.

\subsection{Catchment models}

Flow time series were generated using the CATCHMOD rainfall-runoff model, which is a water balance model used for water resource planning by the UK Environment Agency, and has been described in detail elsewhere (Wilby et al., 1994; Davis, 2001). CATCHMOD is a lumped parameter conceptual model, which allows for the subdivision of the catchment into a number of zones, according to its geological and surface runoff characteristics. Input to the model is in the form of time series of daily rainfall and potential evapotranspiration representative of the entire catchment and 

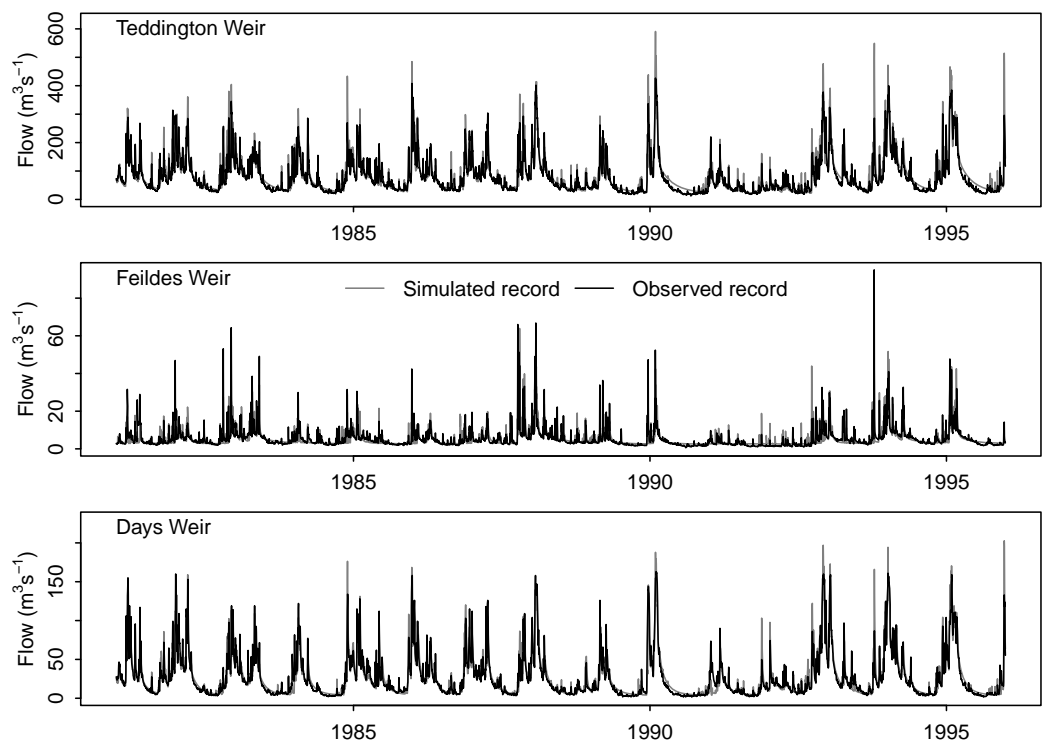

Figure 3. Validation of CATCHMOD reproduction of observed flows. The calibration period against historical flows was 1 January $1961-$ 31 December 1978 for Teddington and Days Weir, and 1 January 1961-31 December 1975 for Feildes Weir. The validation period for all catchments was 1 January 1979-31 December 2002.

the output is a time series of the daily flow at the catchment output. Three parameterizations of this model were used to produce flow series for each of the three input subcatchments locations of the water resource model. Each of these involves three zones, representing clay, limestone, and urban regions. Parameters were chosen by optimization of the Nash-Sutcliffe efficiency in reproducing historically observed flow, and validated by comparison with flows in a different historical period (see Manning et al., 2009, and Fig. 3). The following Nash-Sutcliffe efficiencies were achieved for each catchment: at Teddington Weir, a calibration of 0.88 and validation of 0.86; at Feildes Weir, a calibration of 0.68 and validation of 0.69; and at Days Weir, a calibration of 0.86 and validation of 0.90 .

The ensemble of 100 future 100-year scenarios of rainfall and PET generated by UKCP09-WG for both the SCN20 and SCN50, alongside the 10 BSL scenarios were used to drive CATCHMOD to produce synthetic river flow data for use as input into the water resource model.

\subsection{Water resource modelling}

To enable assessment of London's Water Resource Zone scenarios. a rule-based water resource management simulation program was developed for this study in the MatLab ${ }^{\circledR}$ programming language. This was parameterized with the same operational rules, flow, demand, and capacity data as the Environment Agency's implementation of the AQUATOR software (Oxford Scientific Software Ltd., 2004) for the Thames Basin but is orders of magnitude faster and able to simulate 100 years' conditions in $\sim 1 \mathrm{~s}$. The London Area Rapid Water Resource Model (LARaWaRM) is a network model comprising nodes and links representing various water resource components and interactions. Nodes can represent diversions, natural lakes, reservoirs, aquifers, wetlands, gauge sites with a defined time-series flow, and demand consumption sites. At each (daily) time step, water is moved according to the input data, with rules defining the behaviour of each node and link, and connectivity between components.

Figure 4 presents a schematic of LARaWaRM which was used to investigate the potential impacts of climate change, socioeconomic change and supply/demand options on the resource system. Synthetic river flows generated by $\mathrm{CATCH}-$ MOD were input into LARaWaRM to evaluate the impacts of the downscaled climate change UKCP09 probabilistic projections.

Drought risk is estimated by the frequency, in terms of the number of days, that a demand saving (DS) measure is imposed. In water resources planning, demand saving measures or levels of service describe the average frequency that a company will apply restrictions on water use, triggered by reservoir control curves. In robust analysis of water resource systems, failure to meet a particular level of service can act as a suitable metric of risk and one against which the effectiveness of interventions to a system can be judged (Hall et al., 2012; Groves and Lempert, 2007). Table 1 describes these levels of service, restrictions and their target frequencies for the Thames Basin.

To explore the impact of population growth on drought risk, population and employment growth estimates were also used to scale current demand. Population estimates were taken from the Greater London Authority's strategic plan for London (GLA, 2011) for up to 2031 and then extrapolated 


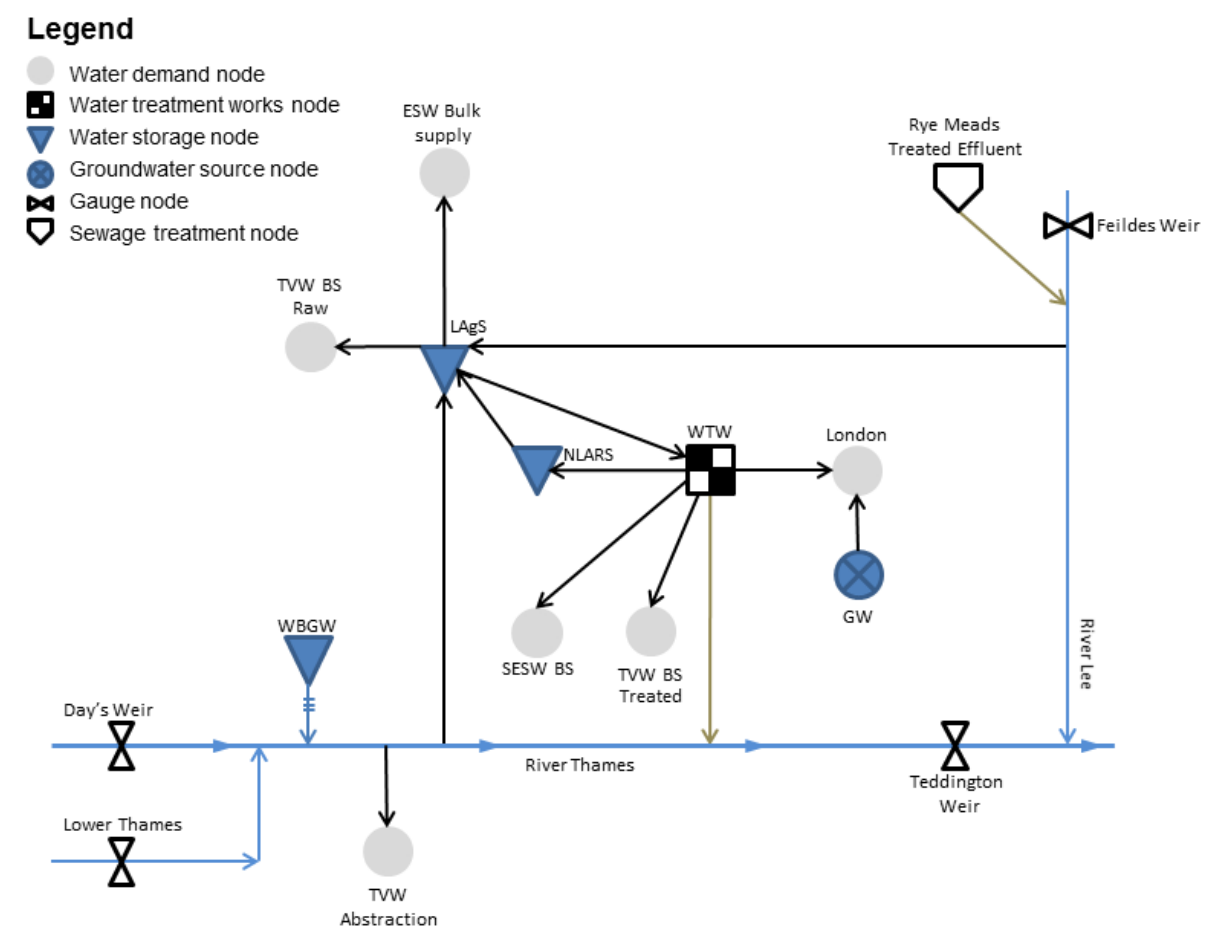

Figure 4. A schematic of LARaWaRM indicating the various water resource system components and interactions. (NB: groundwater is included as an aggregate inflow of $467.4 \mathrm{ML} \mathrm{day}^{-1}$ to meet London's demand. A proportion of the inflow to the water treatment works is leakage; this is equivalent to $12 \%$ of demand and is returned back to the river and modelled as a contribution to the minimum environmental flow.)

Table 1. Levels of service: restrictions and frequency of restrictions (Source: GLA, 2011; Thames Water, 2014). See Table S1 in the Supplement for reservoir total storage capacity trigger levels for the different levels of restrictions.

\begin{tabular}{lll}
\hline Level of service & Restrictions & $\begin{array}{l}\text { Frequency of restrictions } \\
\text { (Thames Water, 2014) }\end{array}$ \\
\hline DS1 & $\begin{array}{l}\text { Media campaigns, additional water efficiency activities, en- } \\
\text { hanced activity, and restrictions to reduce risk to water supply }\end{array}$ & 1 in 5 years on average \\
DS2 & $\begin{array}{l}\text { Enhanced media campaign, customer choice/voluntary con- } \\
\text { straint, sprinkler ban. }\end{array}$ & 1 in 10 years on average \\
& $\begin{array}{l}\text { Temporary Use Ban (formerly hosepipe ban), Drought Direc- } \\
\text { tion 2011 (formerly non-essential use bans) requiring the grant- }\end{array}$ & \\
DS3 & $\begin{array}{l}\text { ing of an Ordinary Drought Order. } \\
\text { Severe water rationing, e.g. rota cuts, stand pipes, i.e. Emer- } \\
\text { gency Drought Order. }\end{array}$ & Never \\
& & \\
\hline
\end{tabular}

at the same average annual growth rate of 51000 to provide an estimate of population for 2050. Employment growth estimates were calculated using the Tyndall Centre for Climate Change's methodology derived for the Urban Integrated Assessment Facility (see Hall et al., 2009; Walsh et al., 2011). In addition, demand per capita was altered to reflect technological advances, such as improved water efficiency measures. By altering the properties of existing links and nodes or introducing new links and nodes into the model domain, a number of supply adaptation options were also investigated.

Adaptation options considered included:
- Demand reduction: sensitivity analysis considering reduction in per capita demand between 0 and $35 \%$, at $5 \%$ intervals which represent a range of behavioural and technical efficiencies;

- Desalination plant: capacity providing $150 \mathrm{ML} \mathrm{day}^{-1}$, which represents the Thames Water site at Beckton;

- Leakage reduction: in 2010/11, Thames Water reported leakage losses of $26 \%$; the UK water company average is $18.5 \%$ (GLA, 2011), a linear reduction in leakage to $18.5 \%$ by 2050 is applied; 

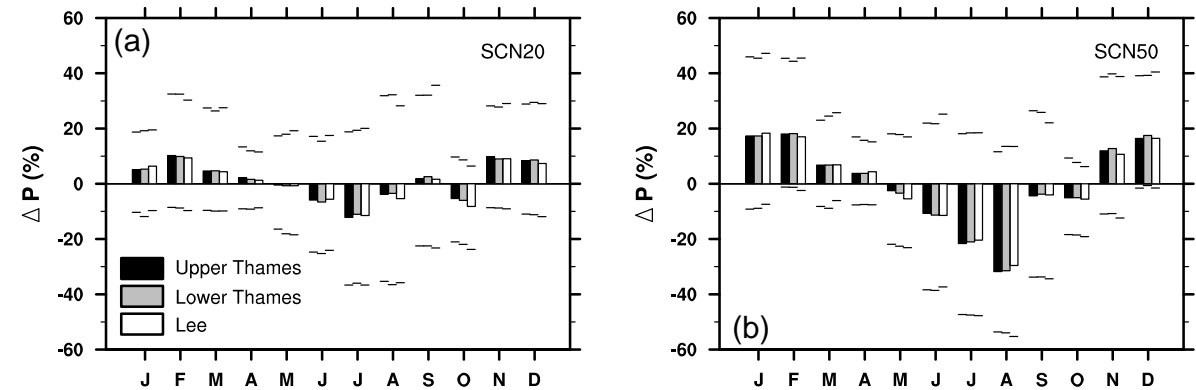

Figure 5. Percentage change in precipitation for (a) SCN20 and (b) SCN50. The bars denote the median change from the 100-member ensemble; the upper and lower horizontal lines indicate the ensemble 90th and 10th monthly percentiles, respectively.

- New reservoir: storage capacity of 100 million $\mathrm{m}^{3}$ added to the 2050 runs, as realistically such infrastructure is planned over a 30-year timeframe;

- Combinations of the above: the model's computational efficiency enables a range of different combinations of adaptation options to be tested.

\section{Results}

\subsection{Changes in rainfall and potential evapotranspiration}

For each sub-catchment, mean monthly precipitation was calculated for each of the 100 simulated series for SCN20 and SCN50 and changes were examined relative to the median monthly precipitation derived from the 10 BSL simulations. There is relative uniformity across the three subcatchments with a greater range in projections in summer months - the median estimate of change indicates a pattern of wetter winters and drier summers. For SCN20, projected changes in mean precipitation are relatively small, $<+10 \%$ in winter and $>-10 \%$ in summer. However, these increase in magnitude to $\sim+15$ to $+20 \%$ in winter and $\sim-10$ to $-30 \%$ in summer for SCN50 (see Fig. 5). The ensemble of rainfall variation shows that there could be substantially greater pressure on water resources - the 10th percentile indicating decreases projected for all seasons; for SCN50 this represents a typical decrease of $\sim 45 \%$ during summer with a small $(<\sim-5 \%)$ decrease in winter. However, the 90th percentile suggests less stress with an increase in precipitation throughout the year. Mean seasonal precipitation was also calculated for each season and expressed as an anomaly from the long-term mean to determine the longest sequence of negative seasonal anomaly. This suggested the potential lengthening of periods with below-average rainfall - for BSL the longest sequence was 10, whereas for SCN50 it was 18. However, we note that a limitation of applying change factors through a weather generator to assess future projections in rainfall is that it does not readily produce the longer se- quences of dry periods (Wilby et al., 2004) that may produce multi-seasonal droughts and hence stress the water supply system.

The projected change in occurrence of precipitation was also assessed through the examination of dry day probabilities (PDD). Figure 6a demonstrates that for SCN20 the central estimate shows relatively little change in PDD relative to the BSL during winter and spring but that PDD is projected to increase in summer. For SCN50 (Fig. 6b) there remains little change in PDD during winter but there is a further increase between May and October with the median estimate of up to $\sim 0.8$ in August.

Mean daily PET is projected to increase throughout the year (Fig. 6c and d). For SCN20, the largest increase occurs in summer, the central estimate indicating an absolute increase of $\sim+0.3 \mathrm{~mm} \mathrm{~d}^{-1}$ relative to a BSL value of $\sim 3.0 \mathrm{~mm} \mathrm{~d}^{-1}$. For winter, the change is smaller, $\sim+0.1 \mathrm{~mm} \mathrm{~d}^{-1}$ relative to a BSL value of $\sim 0.4 \mathrm{~mm} \mathrm{~d}^{-1}$. However, these figures represent a larger relative increase in PET in winter. For SCN50, the increase in summer is $\sim+0.6 \mathrm{~mm} \mathrm{~d}^{-1}$ with an additional increase in winter $\sim+0.1 \mathrm{~mm} \mathrm{~d}^{-1}$. These combined changes demonstrate potential future pressure on water resources arising from climate change which is investigated further through the application of these ensemble projections to a rainfall-runoff model and water resource model for the Thames.

\subsection{Changes in river flows}

Precipitation and PET series for the two 100-member future scenario ensembles are used to generate river flows for the three sub-catchments using the CATCHMOD rainfall-runoff model. Figure 7 shows the percentage change in monthly and seasonal flows for each sub-catchment for SCN20 and SCN50 compared to the $10 \mathrm{BSL}$ simulations. The bars show the median changes in flows, with the upper and lower horizontal bars showing the 10th and 90th percentiles, indicating the degree of uncertainty in the climate projections. Generally there is a large spread in the projections. For SCN20, from February to June there is a small increase in median flows for the Upper Thames, and an even smaller increase 

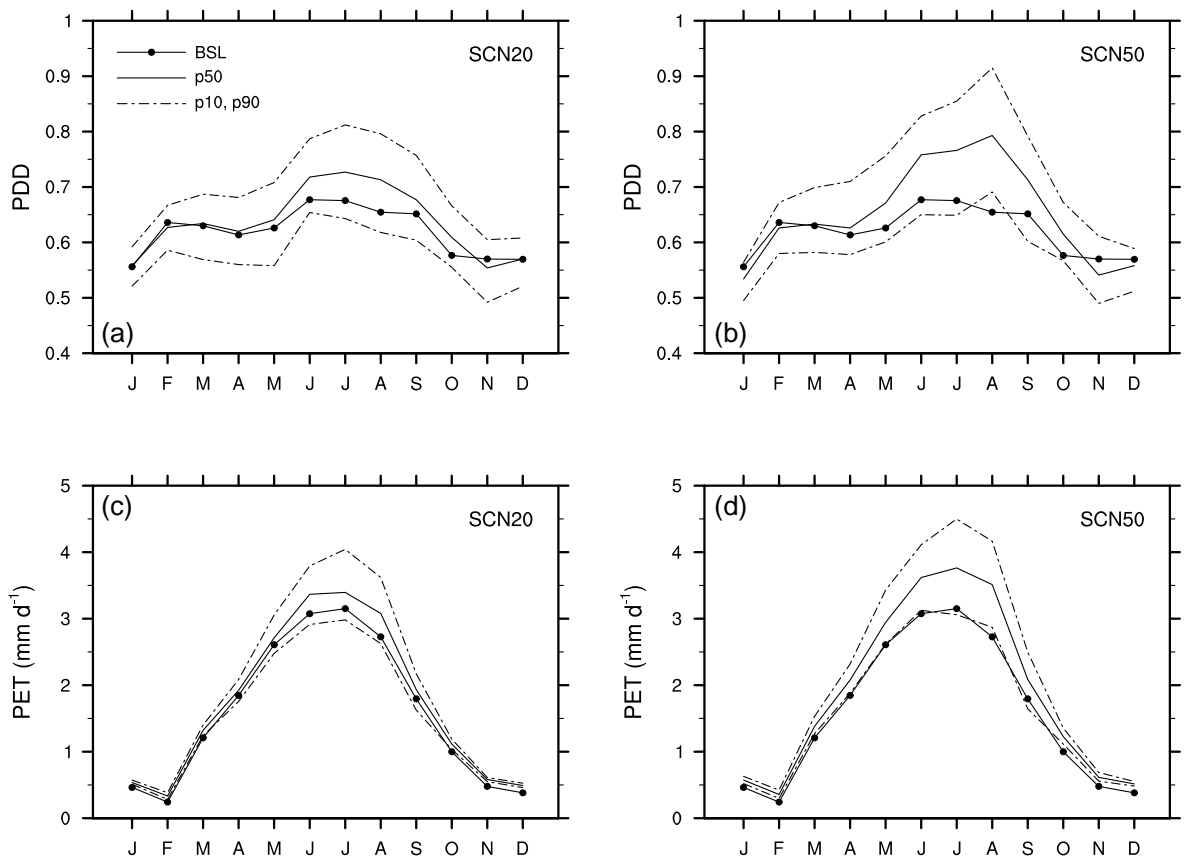

Figure 6. Projected and baseline (BSL) statistics for dry day probability (PDD) and mean daily PET for SCN20 and SCN50 for Thames catchment. For the ensemble projections the central estimate (p50) and upper and lower estimates represented by the 90th (p90) and 10th (p10) percentiles are shown.
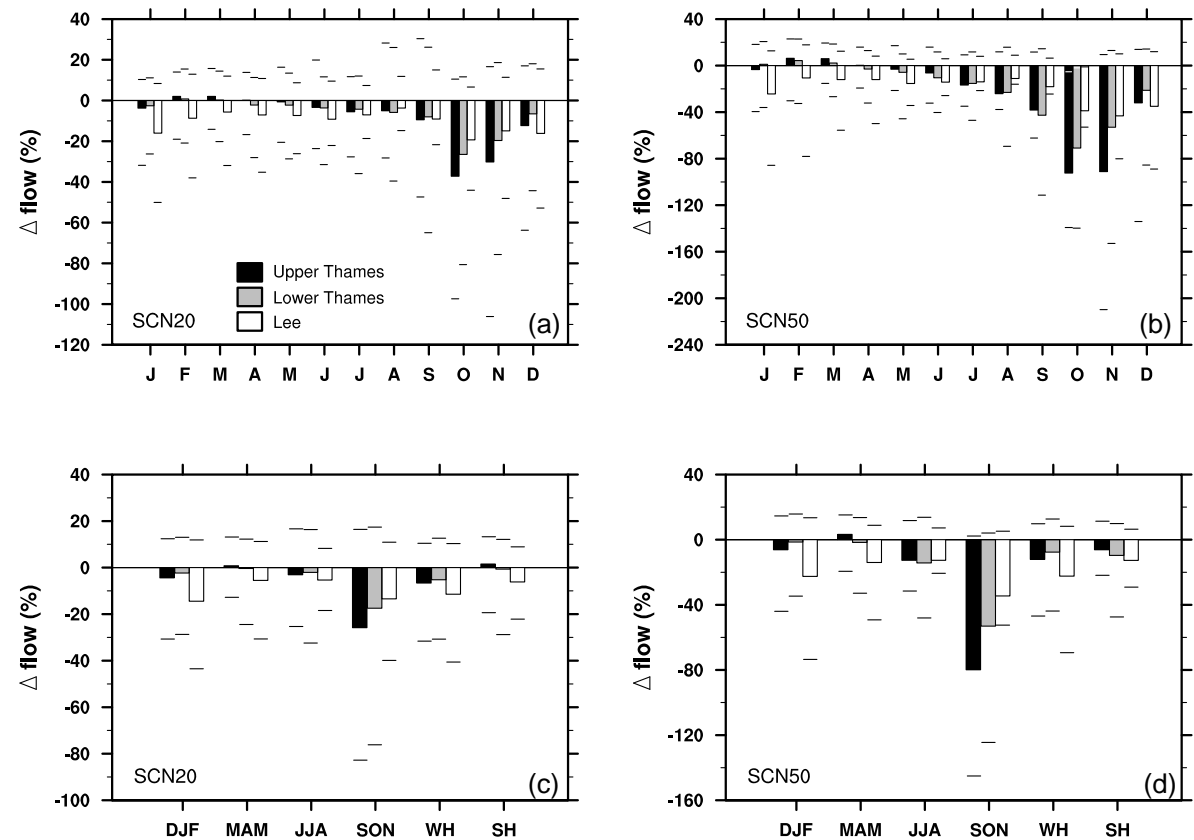

Figure 7. Percentage change in Upper Thames, Lower Thames, Lee catchments for monthly river flows for (a) SCN20, monthly flows, (b) SCN50, monthly flows, (c) SCN20, seasonal flows, (d) SCN50, seasonal flows (standard seasons plus winter half year (WH) and summer half year $(\mathrm{SH})$ ). The bars denote the median change from the 100-member ensemble, the upper and lower horizontal lines indicate the ensemble 90th and 10th percentiles, respectively. 

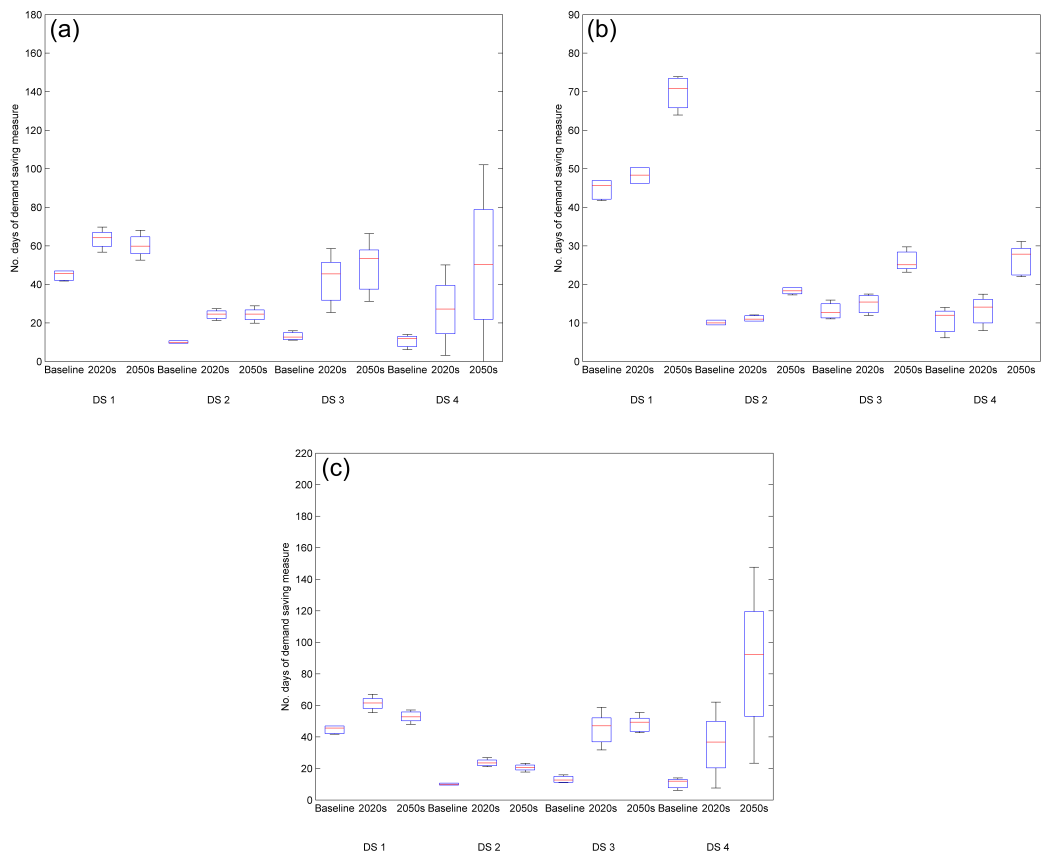

Figure 8. Number of demand saving days per 100 years (DS1-DS4) under BSL, SCN20, and SCN50 scenarios for (a) climate change projections only; (b) population growth projections only; (c) both climate and population projections, in all cases per capita demand remains constant at present-day value. Box plots indicate the median, 25th, and 75th percentile values; whiskers show the 10th and 90th percentile values.

in the Lower Thames, with the Lee showing a decrease during these months. All other months for each catchment show decreases in median flows, with substantial decreases from July to December in SCN50. Plotted seasonally, the greatest decreases are evident in the autumn months (September, October, and November). Mean estimates for flow quantiles (not shown) at Kingston, the outlet of the catchment, when compared with BSL, indicate a decrease for SCN20 across the entire flow duration curve, with greater decreases in Q90 and Q95 of 14 and $15 \%$, respectively. For SCN50, the simulations also show a decrease in mean flow quantiles across the entire flow duration curve, with the exception of higher flows, i.e. Q5 and above. Decreases in lower flows are more substantial, with mean decreases of 33 and $37 \%$ in Q90 and Q95, respectively.

\subsection{Water resource availability}

Initial analysis determined the relative impacts of climate change and population growth on drought risk, in terms of change in frequency of demand saving measures derived from LARaWaRM. Figure 8 presents the number of days that each of the DS measures are implemented for the baseline, SCN20, and SCN50 runs for (i) the climate projections only; (ii) changes in population growth only (where per capita allocation remains the same); and (iii) climate and population growth signals combined. Both climate projections (i) and population growth scenarios (ii) increase the frequency of all DS measures. The climate scenarios introduce a greater degree of variability and uncertainty into the frequency estimations which increases as the severity of the DS measure worsens. Considering the population signal alone, there is a smaller increase in SCN20 frequencies compared to the BSL scenarios. However, there is a greater shift in median values from SCN20 to SCN50. The relative contribution to drought risk from population growth is greater than that from the climate projections. However, these simulations assume that per capita demand remains the same as present in SCN20 and SCN50.

Figure 9 demonstrates the effectiveness of reducing demand, i.e. per capita allocation, on the frequency of DS4 measures for BSL, SCN20, and SCN50. Although probably unrealistic, a reduction in per capita allocation of $35 \%$ would eliminate the need for drought orders in the 2020s. Even a small decrease of $3.75 \%$ in SCN20 reduces the median frequency by $50 \%$. However, by the 2050s the growing population and intensification of the climate change signal means that the $35 \%$ reduction in per capita allocation is no longer effective, suggesting that new supply options may be required to complement demand management strategies by the 2050s.

Therefore, we also investigated a number of supply options to supplement the currently available water. Figure 10 presents the frequency of DS4 days for a number of supply adaptation options for the 2020s and 2050s: (i) a desalination plant: capacity of providing $150 \mathrm{ML} \mathrm{day}^{-1}$, which rep- 


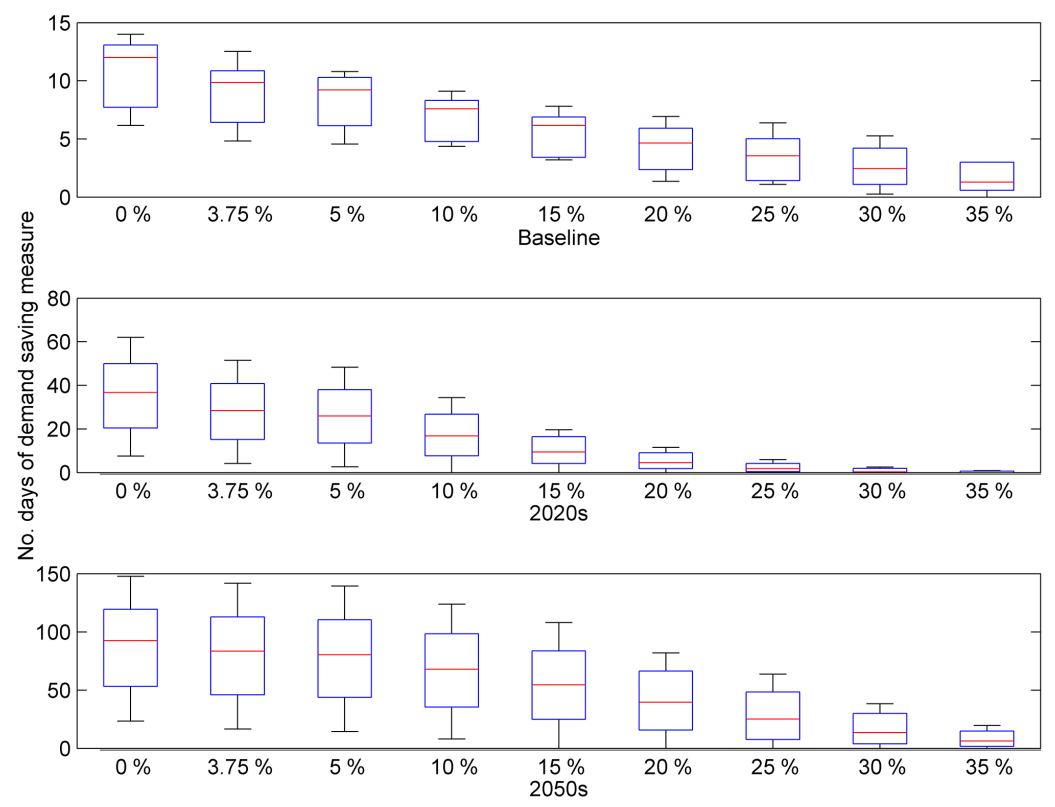

Figure 9. Number of DS4 days per 100 years for BSL, SCN20, and SCN50 under climate and population projections, for a range of reductions in per capita demand. Box plots indicate the median, 25th, and 75th percentile values; whiskers show the 10th and 90th percentile values.

resents the Thames Water site at Beckton; (ii) a linear reduction in leakage to $18.5 \%$ by 2050 is applied to the simulations; (iii) reservoir: storage capacity of 100 million $\mathrm{m}^{3}$ is added to the 2050 runs as realistically such infrastructure is planned over a 30-year timeframe; (iv) various combinations of (i), (ii) and (iii). In addition, results are shown for all cases with no reduction in per capita demand and for a reduction in per capita demand of $15 \%$ by 2020 and $30 \%$ by 2050 . Per capita demand is reduced by $15 \%$ in 2020 to bring this in line with the UK's average per capita usage. By 2050 it is reduced by a further 15 to $30 \%$ to reflect the potential impact of demand saving measures, e.g. water meters alone can create water savings of 10-15\% per household (Environment Agency, 2007b).

Individually, all options considered have a positive effect in reducing the frequency of DS4 measures. The availability of $150 \mathrm{ML} \mathrm{day}^{-1}$ from the desalination plant in 2020 reduces the median frequency value by around $100 \%$; however, its effectiveness is diluted by 2050. For SCN50, reducing leakage has a greater impact than the desalination plant itself. Combinations of adaptation options improve the situation further. To obtain a $100 \%$ reduction in the median number of DS4 days by 2050, a combined contribution from leakage reduction and a new storage reservoir is necessary. An additional $37.5 \%$ improvement can be obtained by adding the contribution of the desalination plant to this portfolio. A $15 \%$ reduction in overall demand in 2020 and $30 \%$ in 2050 has a greater impact on reducing the frequency of DS4 days than any of the individual or combined supply options. Introducing demand reduction also reduces the variability significantly.

\section{Discussion}

Between 2003 and 2006, England and Wales reported the third lowest rainfall since 1932-1934; the Thames and the south-east experienced exceptional regional rainfall deficits. Of particular importance was the disproportionate concentration of overall rainfall deficit in the winter and spring, when typically modest evaporation losses allow the bulk of reservoir replenishment and aquifer recharge (Marsh, 2007). Drought Severity Index analysis for the Thames catchment, as for other water resource regions in the south, shows an historical increase in drought intensity and frequency of drought months in both wet and dry seasons, as well as frequency of drought events with persistence of at least 3 or 6 months (Rahiz and New, 2013). In this study, the combined projection of increased PDD and PET during summer months and lasting further into autumn, highlight the potential for increased frequency of such climate-driven water resource pressures in the future.

The largest decreases in river flows are projected for September to November; with the greatest effects being decreases in low flows. At the outlet of the catchment projected mean change in Q90 is a $14 \%$ decrease, with a similar value, $15 \%$ for Q95 (SCN20). However, the changes are much greater for SCN50 - 33\% for Q90 and 37\% for Q95. Manning et al. (2009), found mean decreases in Q95 of $45 \%$ using the HadRM $3 \mathrm{H}$ model and $37 \%$ using the HadRM3P model for the 2080s, using the medium-high scenario for the Thames. In their UK-wide study, Christierson et al. (2012) highlight that the largest flow decrease was found in the Thames, Anglian, and Severn river basin regions, with 

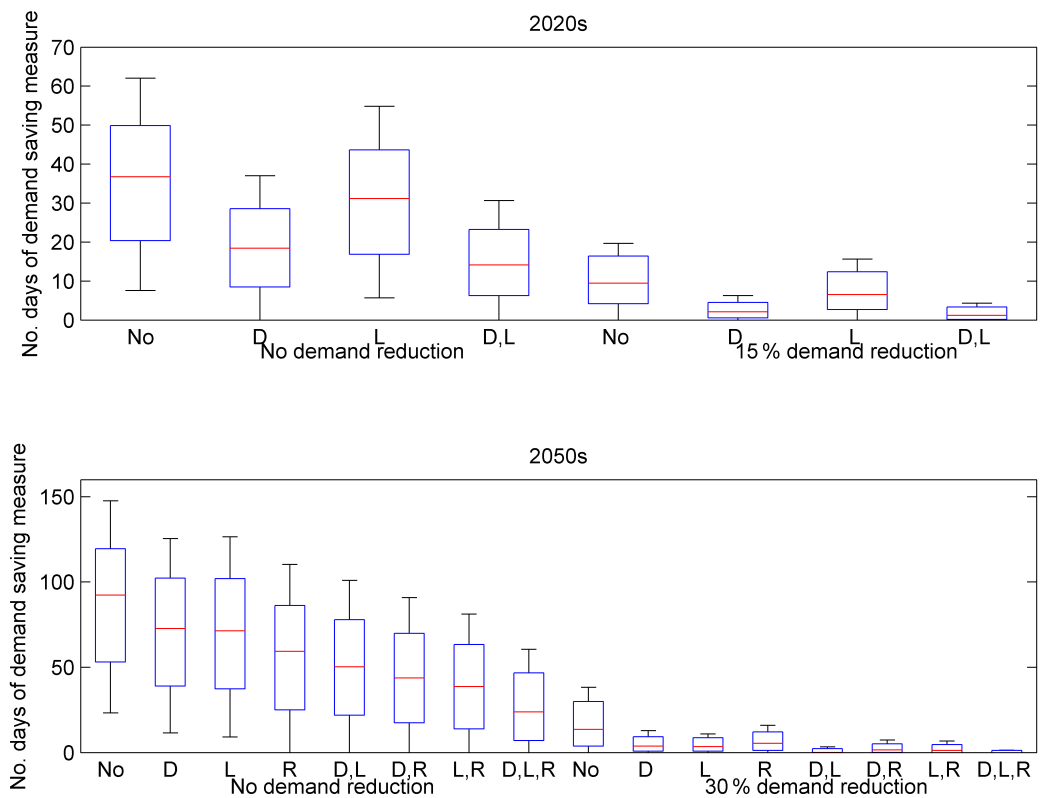

Figure 10. Number of DS4 days per 100 years for SCN20 and SCN50 under climate and population projections, given a range of supply and demand management options. No = no supply measures; $\mathrm{D}=$ desalination plant providing up to $150 \mathrm{ML}^{\text {day }}{ }^{-1} ; \mathrm{L}=$ leakage targets $(24.2 \%$ by $2020 ; 18.5 \%$ by 2050$) ; \mathrm{R}=$ reservoir of 100 million $\mathrm{m}^{3}$. Results are presented with no reduction in per capita demand and $15 \%$ reduction in 2020 and $30 \%$ reduction in 2050. Box plots indicate the median, 25th, and 75th percentile values; whiskers show the 10th and 90th percentile values.

a high probability assigned to decline in summer flows. They also conclude that the dispersion of distributions in projected monthly flows for the Thames catchment to be larger than the range of natural variability.

There have been five major water resource droughts in the Thames catchment over the last 90 years (Thames Water, 2014): 1920-1921; 1933-1934; 1943-1944; 1975-1976; and 2010-2012. Most recently, the 24-month period from April 2010 to March 2012 was the driest in the 128-year record for the Thames catchment. During this period, intensive media campaigns highlighted the drought and promoted water efficiency; in 2012 both a Temporary Use Ban and Non-Essential Use ban were implemented (i.e. Level of Service 3 restrictions). Our results (see Fig. 8a) clearly show that existing water supplies are sensitive to changing climate. In particular, the requirement for DS3 and DS4 measures is projected to increase by the 2020 s and more so by the 2050s. Similarly, Darch et al. (2011) found their central estimates of supply-demand deficiency for the London Water Resource Zone may increase from $51 \mathrm{ML} \mathrm{day}^{-1}$ under the 2020s medium emissions scenario to $516 \mathrm{ML} \mathrm{day}^{-1}$ under the 2080s high emissions scenario, albeit with large uncertainties. Although they considered a wider range of climate projections, they did not consider how such impacts may be compounded by population growth; resulting in increasing demand for resources.

Population growth, especially in London and the southeast will inevitably place increased pressure on already limited water resources. By 2031, the GLA (2011) expect London's population to increase by 16-21\%. Our analysis demonstrates the potential impacts of both climate change and population growth on water availability. Population projections are available up to 2031, beyond which we have extrapolated the average growth rate to 2050. It could be argued that this may be a conservative estimate as London continues to regenerate, expand, and invest in major infrastructure projects to attract increased investment and agglomerations of organizations, and hence ultimately population. However, both climate changes and population growth will occur simultaneously, therefore the starting point for assessing the benefit of any supply and demand adaptation measures needs to be based upon the projections shown in Fig. 8c. When comparing the expected frequency of level of service/demand saving measures from Thames Water (see Table 1), results show that targets are increasingly less likely to be met. For example, currently the target is to never implement DS4 measures, but our analysis indicates that these may be required once every 2 years by the 2020 s and once every year by the $2050 \mathrm{~s}$.

Globally, the greatest demand for water is driven by agriculture and industry; however, in the UK, given reduced industrial and mining demand for water, more emphasis has been placed on the demand management of potable water (McDonald, 2007). Supply-side solutions have dominated water management, with little attention given to long-term demand forecasting. Parker and Wilby (2013) reviewed ap- 
proaches to water demand estimation and forecasting for daily-seasonal and yearly-decadal timescales for household water use. They concluded that little consideration has been given to UK household water demand estimation and forecasting under a changing climate. However, water demand management is increasingly recognized as a "low regret" adaptation from both a financial and environmental point of view, which can be implemented at a range of scales from individuals and households to communities. Water meters have been shown to decrease water use by $10-15 \%$ per household (GLA, 2011), as well as improve energy efficiency, given the substantial proportion of energy used to heat water within a household. The GLA have ambitious targets for the installation of water meters in London properties (all houses and blocks of flats by 2020 and all individual flats by 2025; GLA, 2011). There are no guarantees on the uptake of demand saving measures such as water meters, grey water recycling, or water efficient appliances; however, our analysis (see Fig. 10) has demonstrated that even small reductions in per capita demand can reduce the median frequency of DS4 measures, e.g. by $50 \%$ by the 2020 s. A $35 \%$ reduction in per capita demand by 2020 , which is perhaps unrealistic, would eliminate the risk of drought orders. The Future Water Strategy (Defra, 2008) suggests a target of reducing per capita usage from 150 to $130 \mathrm{~L} \mathrm{day}^{-1}$, a $13 \%$ reduction by 2030 . By 2050 , even a $35 \%$ reduction in per capita demand is no longer effective and new supply options need to be considered.

The London Water Resource Zone supply-demand deficit is currently finely balanced and it is recognized that a new supply resource will be required by the end of the 2020s (Thames Water, 2014). The UK's first desalination plant built in the Thames Gateway became operational in 2010. Our results show that this new resource increases the reliability of supply through the 2020s; however, by the 2050s, consistent with Borgomeo et al. (2014), our analysis shows that further new resource may be required. Here, we go further to consider additional supply options. A new reservoir with a storage capacity of 100 million $\mathrm{m}^{3}$ is a beneficial new resource in the 2050s; however, in addition to the socioeconomic costs of new schemes, climate sensitivity of both supply and demand reduction options also need to be considered. For instance leakage reduction and artificial recharge are not as sensitive to externalities as new storage options which require adequate precipitation or personal usage reductions given a warmer climate. In their 2011 study, Darch et al. found that the cost effectiveness of new reservoir options for the Thames catchment are sensitive to assumptions about climate change. Compulsory metering and leakage reduction schemes were selected under all of the scenarios, with a new reservoir option becoming plausible by the 2050s under medium emissions scenarios. By the 2080s, it was found that a strategic transfer, e.g. Severn-Thames would also be necessary; alternatives such as indirect reuse and further desalination capacity were also considered but are much more expensive and carbon intensive (Darch et al., 2011).
Results from this study advocate the twin-track approach of demand reductions and new supply options to minimize the risk of severe imposed restrictions on water resources. Considering a plausible representation of future climate, demand scenarios and potential adaptation strategies will aid water managers' assessment of where vulnerabilities occur. Hall and Borgomeo (2013) proposed a framework to test strategies for adapting to risks that enables testing large numbers of synthetic hydrological sequences and allows exploration of different sources of uncertainty including climate, catchment responses, and demands. In their case study on Adelaide's southern water supply system, Beh et al. (2015a, b) and Paton et al. (2014) demonstrate a multi-objective evolutionary algorithm framework to consider the trade-offs between reducing greenhouse gas emissions while planning sustainable urban water supply systems. Applied to North Carolina, Zeff et al. (2014) investigated how more flexible and adaptable water supply portfolios can be implemented alongside financial mitigation tools to reduce trade-offs between fluctuations of revenues and costs of implementing new solutions. Haasnoot et al. (2014) demonstrate the development of adaptation pathways whereby environment and policy responses are analysed through time to develop an ensemble of plausible futures to support decision making under uncertainty. Applying the approach and outcomes from this research in such risk frameworks would be valuable in considering costs, benefits, and trade-offs of adaptation measures. This would facilitate adaptive strategies that are able to evolve as new information becomes available; this is particularly useful given climate model, demographic, and supply uncertainty.

This study has advanced understanding of the potential future water resource risk and possible adaptation options for managing these risks for the Thames catchment. However, the study has a number of limitations, in particular one model chain and hence uncertainties were considered; multiple models and methods would result in further confidence in the results and interpretations. We used the UKCP09 probabilistic climate scenarios only for the medium emission scenario, for two time periods; although Harris et al. (2013) indicate that for the 2080s the uncertainty in the UKCP09 PPE is the cause of a greater proportion of uncertainty in flow and water shortage probability than is caused by the emissions scenario. We used only one hydrological model, CATCHMOD, and one parameter set, although this has been extensively tested for the Thames catchment (e.g. Davis, 2001; Wilby, 2005; Wilby and Harris, 2006; Manning et al., 2009). Wilby and Harris (2006) showed how both choice of hydrological model and choice of model parameters can affect the outcome of the modelling study. We have only considered the impacts of climate change and demand change on water resource availability at defined points in the future, i.e. 2020s and 2050s; however, there is a growing practical interest on how changes play out throughout a planning horizon such as an Asset Management Plan period. For this a tran- 
sient implementation of the single-site NSRP model and Climatic Research Unit (CRU) weather generator (Burton et al., 2010b; Blenkinsop et al., 2013) could be implemented (e.g. Goderniaux et al., 2011).

\section{Conclusions}

The application of a sequence of models, including an extension of the UKCP09 weather generator that generates downscaled, probabilistic projections of rainfall on a grid over the Thames catchment, indicates that the hazard of inadequate water supply is expected to increase as a function of both climatic and socioeconomic drivers. Here we show that these hazards can be managed most effectively through a portfolio of adaptation measures.

Population growth exhibits a greater contribution to drought risk than climate projections. An extreme reduction of $35 \%$ in daily per capita allocation would be necessary to offset application of drought orders by 2020. However, a relatively small decrease would have a significant impact, yet moving towards 2050 the need for new supply options could intensify. We found that increased supply from various adaptation options may compensate for increasingly variable flows; however, without reductions in overall demand for water resources such options will not be sufficient to adapt to both climate change projections and a growing population. For example, a $100 \%$ reduction in the median number of DS4 days by 2050 can be achieved through leakage reduction and a new storage reservoir. An additional $37.5 \%$ improvement can be obtained by adding the contribution of the desalination plant to this portfolio. A $15 \%$ reduction in overall demand in 2020 and $30 \%$ in 2050 has a greater impact on reducing the frequency of DS4 days than any of the individual or combinations of supply options. Water demand reductions are clearly important in reducing water resource deficits; however, given projected population growth these will need to be significant to offset demand increases alongside climate change.

Like other cities, London is at risk and needs to adapt to a range of climate-related hazards, e.g. flooding, urban heat, and subsidence (Hallett, 2013) that need to be managed synergistically to avoid any potential conflicts (Dawson, 2007). Many urban areas have set greenhouse gas emission reduction targets (Heidrich et al., 2013). Reducing water demand can reduce energy consumption, as water use in the home accounts for $89 \%$ of all carbon emissions resulting from water use (Environment Agency, 2008). Conversely, the introduction of energy intensive adaptation options such as desalination plants or inter-basin transfers may conflict emission reduction targets.

Given the typical investment timescale to plan, approve, and implement changes, decisions for water management infrastructure development can have consequences over long timescales (Hallegatte, 2009). When considering any major infrastructure investment and development, such as a new reservoir, a range of environmental, economic, and social consequences need to be critically analysed. The approach demonstrated here can be used to assess a range demand and supply adaptations that can be implemented and be effective on short and long timescales to make robust decisions about water resource management.

This study of the Thames catchment and subsequent analysis has highlighted the following priorities for future research. Firstly, which will be addressed in a forthcoming paper, is an extension of the climate scenarios to include the 2080s time period, coupled with the application of a spatial weather generator feeding a physically based, spatially distributed hydrological model which will allow better representation of both the climatological and land cover heterogeneity of the catchment. Furthermore, it will enable changes in land cover, i.e. increasing urban areas to be considered. Secondly, recognising the importance of groundwater in the Thames catchment and hence the potential impact that multi-season droughts may have on the area, further research is needed to understand how trends in such phenomena may affect or influence the choice of adaptation options. This, alongside a third research priority looking more generally about the sequencing of implementation of adaptation options over indicative planning horizons taking account of trade-offs with reducing greenhouse gas emissions or investment portfolios could make use of more robust decision making frameworks under uncertainty such as those proposed by for example Beh et al. (2015b) or Haasnoot et al. (2014).

\section{The Supplement related to this article is available online at doi:10.5194/hess-20-1869-2016-supplement.}

Acknowledgements. This work was undertaken as part of the SWERVE project which was funded by the Engineering and Physical Sciences Research Council (EPSRC) project no. EP/F037422/1. Richard Dawson was supported by an EPSRC Fellowship EP/H003630/1, and Hayley Fowler was supported by a NERC Postdoctoral Fellowship award (NE/D009588/1). Hayley Fowler is funded by the Wolfson Foundation and the Royal Society as a Royal Society Wolfson Research Merit Award (WM140025) holder. We would like to thank the reviewers for their valuable suggestions and comments.

Edited by: D. Solomatine

\section{References}

Beh, E. H. Y., Maier, H. R., and Dandy, G. C.: Scenario driven optimal sequencing under deep uncertainty, Environ. Modell. Softw., 68, 181-195, doi:10.1016/j.envsoft.2015.02.006, 2015a. 
Beh, E. H. Y., Maier, H. R., and Dandy, G. C.: Adaptive, multiobjective optimal sequencing approach for urban water supply augmentation under deep uncertainty, Water Resour. Res., 51, 15291551, doi:10.1002/2014WR016254, 2015b.

Blanc, J., Hall, J. W., Roche, N., Dawson, R. J., Cesses, Y., Burton, A., Kilsby, C. G.: Enhanced efficiency of pluvial flood risk estimation in urban areas using spatial-temporal rainfall simulations, Journal of Flood Risk Management, 5, 143-152, doi:10.1111/j.1753-318X.2012.01135.x, 2012.

Blenkinsop, S. and Fowler, H. J.: Changes in drought frequency, severity and duration for the British Isles projected by the PRUDENCE regional climate models, J. Hydrol., 342, 50-71, doi:10.1016/j.jhydrol.2007.05.003, 2007.

Blenkinsop, S., Harpham, C., Burton, A., Goderniaux, P., Brouyère, S., and Fowler, H. J.: Downscaling transient climate change with a stochastic weather generator for the Geer catchment, Belgium, Clim. Res., 57, 95-109, doi:10.3354/cr01170, 2013.

Borgomeo E., Hall, J. W., Fung, F., Watts, G., Colquhoun, K., and Lambert C.: Risk-based water resources planning: Incorporating probabilistic nonstationary climate uncertainties, Water Resour. Res., 50, 6850-6873, doi:10.1002/2014WR015558, 2014.

Brown, C. and Wilby, R. L.: An alternate approach to assessing climate risks, EOS T. Am. Geophys. Un., 93, 401-402, doi:10.1029/2012EO410001, 2012.

Brown, C., Ghile, Y., Laverty, M., and Li, K.: Decision scaling: Linking bottom-up vulnerability analysis with climate projections in the water sector, Water Resour. Res., 48, W09537, doi:10.1029/2011WR011212, 2012.

Burke, E. J. and Brown, S. J.: Regional drought over the UK and changes in the future, J. Hydrol., 394, 471-485, doi:10.1016/j.jhydrol.2010.10.003, 2010.

Burton, A., Kilsby, C. G., Fowler, H. J., Cowpertwait, P. S. P., and O'Connell, P. E.: RainSim: A spatial-temporal stochastic rainfall modelling system, Environ. Modell. Softw., 23, 1356-1369, doi:10.1016/j.envsoft.2008.04.003, 2008.

Burton, A., Fowler, H. J., Kilsby, C. G., and O'Connell P. E.: A stochastic model for the spatial-temporal simulation of nonhomogeneous rainfall occurrence and amounts, Water Resour. Res., 46, W11501, doi:10.1029/2009WR008884, 2010a.

Burton A., Fowler, H. J., Blenkinsop, S., and Kilsby C. G.: Downscaling transient climate change using a Neyman-Scott Rectangular Pulses stochastic rainfall model, J. Hydrol., 381, 18-32, doi:10.1016/j.jhydrol.2009.10.031, 2010b.

Burton, A., Glenis, V., Jones, M. R., and Kilsby, C. G.: Models of daily rainfall cross-correlation for the United Kingdom, Environ. Modell. Softw., 49, 22-33, doi:10.1016/j.envsoft.2013.06.001, 2013.

Christensen, N. S. and Lettenmaier, D. P.: A multimodel ensemble approach to assessment of climate change impacts on the hydrology and water resources of the Colorado River Basin, Hydrol. Earth Syst. Sci., 11, 1417-1434, doi:10.5194/hess-11-14172007, 2007.

Christierson, B., Vidal, J. P., and Wade, S. D.: Using UKCP09 probabilistic climate information for UK water resource planning, J. Hydrol., 424-425, 48-67, doi:10.1016/j.jhydrol.2011.12.020, 2012.

Cloke, H. L., Wetterhall, F., He, Y., Freer, J. E., and Papenberger, F.: Modelling climate impact on floods with ensem- ble climate projections, Q. J. Roy. Meteor. Soc., 139, 282-297, doi:10.1002/qj.1998, 2013.

Coulthard, T. J., Ramirez, J., Fowler, H. J., and Glenis, V.: Using the UKCP09 probabilistic scenarios to model the amplified impact of climate change on drainage basin sediment yield, Hydrol. Earth Syst. Sci., 16, 4401-4416, doi:10.5194/hess-16-44012012, 2012.

Cowpertwait, P. S. P.: A generalized spatial-temporal model of rainfall based on a clustered point process, P. R. Soc. A, 450, 163175, doi:10.1098/rspa.1995.0077, 1995.

Darch, G., Arkell, B. and Tradewell, J.: Water resource planning under climate uncertainty in London, Atkins Report (Reference 5103993/73/DG/035) for the Adaptation Sub-Committee and Thames Water, Atkins, Epsom, 2011.

Davis, R. J.: The effects of climate change on river flows in the Thames Region, Hydrology and Hydrometry report 00/04, Environment Agency, Reading, UK, 2001.

Dawson, R. J.: Re-engineering cities: a framework for adaptation to global change, P. Roy. Soc. Lond. A Mat., 365, 3085-3098, doi:10.1098/rsta.2007.0008, 2007.

Defra: Future Water: the Government's Water Strategy for England, London: TSO Cm7319, 2008.

Dessai, S. and Hulme, M.: Assessing the robustness of adaptation decisions to climate change uncertainties: a case study on water resources management in the East of England, Global Environ. Chang., 17, 59-72, doi:10.1016/j.gloenvcha.2006.11.005, 2007.

Environment Agency: Water for the Future: Managing water resources in the South East of England - A discussion document, Environment Agency, Bristol, 2007a.

Environment Agency: Towards water neutrality in the Thames Gateway: summary report, Science Report SC060100/SR3, Environment Agency, Bristol, 2007b.

Environment Agency: Greenhouse gas emissions of water supply and demand management options, Science Report - SC070010, Environment Agency, Bristol, 2008.

Environment Agency: Thames catchment abstraction licensing strategy, Environment Agency, Bristol, 2014.

GLA (Greater London Authority): Securing London's Water Future, The Mayor's Water Strategy, Greater London Authority, 2011.

Goderniaux, P., Brouyère, S., Blenkinsop, S., Burton, A., Fowler, H. J., Orban, P., and Dassargues, A.: Modeling climate change impacts on groundwater resources using transient stochastic climatic scenarios, Water Resour. Res., 47, W12516, doi:10.1029/2010WR010082, 2011.

Groves, D. G. and Lempert R. J.: A new analytic method for finding policy-relevant scenarios, Global Environ. Chang., 17, 7385, doi:10.1016/j.gloenvcha.2006.11.006, 2007.

Groves, D. G., Yates, D., and Tebaldi, C.: Developing and applying uncertain global climate change projections for regional water management planning, Water Resour. Res., 44, W12413, doi:10.1029/2008WR006964, 2008.

Hall, J. W. and Borgomeo, E.: Risk-based principles for defining and managing water security, Philos. T. R. Soc. A, 371, doi:10.1098/rsta.2012.0407, 2013.

Hall, J. W., Dawson, R. J., Walsh, C. L., Barker, T., Barr, S. L., Batty, M., Bristow, A. L., Burton, A., Carney, S., Dagoumas, A., Evans, S., Ford, A. C., Glenis, V., Goodess, C. G., Harpham, C., Harwatt, H., Kilsby, C. G., Kohler, J., Jones, P., Manning, L., 
McCarthy, M., Sanderson, M., Tight, M. R., Timms, P. M., and Zanni, A.: Engineering Cities: How can cities grow whilst reducing emissions and vulnerability?, The Tyndall Centre for Climate Change Research, Newcastle University, 2009.

Hall, J. W., Watts, G., Keil, M., de Vial, L., Street, R., Conlan, K., O'Connell, P. E., Beven, K. J., and Kilsby, C. G.: Towards riskbased water resources planning in England Wales under a changing climate, Water Environ. J., 26, 118-129, doi:10.1111/j.17476593.2011.00271.x, 2012.

Hallegatte, S.: Strategies to adapt to an uncertain climate change, Global Environ. Chang., 19, 240-247, doi:10.1016/j.gloenvcha.2008.12.003, 2009.

Hallett, S.: Community Resilience to Extreme Weather the CREW Project: Final Report, available at: http://www. extreme-weather-impacts.net (last access: 6 January 2015), 2013.

Harris, C. N. P., Quinn, A. D., and Bridgeman, J.: Quantification of uncertainty sources in a probabilistic climate change assessment of future water shortages, Climatic Change, 121, 317-329, 2013.

Haasnoot, M., van Deursen, M. P. A., Guillaume, J. H. A., Kwakkel, J. H., van Beek, E., and Middelkoop, H.: Fit for purpose? Building and evaluating a fast, integrated model for exploring water policy pathways, Environ. Modell. Softw., 60, 99-120, doi:10.1016/j.envsoft.2014.05.020, 2014.

Heidrich, O., Dawson, R. J., Reckien, D., and Walsh C. L., Assessment of the climate preparedness of 30 urban areas in the UK, Climatic Change, 120, 771-784, doi:10.1007/s10584-013-08469, 2013.

Hewitt, C., Mason, S., and Walland, D.: The global framework for climate services, Nature Climate Change, 2, 831-832, doi:10.1038/nclimate1745, 2012.

IPCC: Climate Change 2014: Synthesis Report. Contribution of Working Groups I, II and III to the Fifth Assessment Report of the Intergovernmental Panel on Climate Change [Core Writing Team, Pachauri, R. K. and Meyer, L. A.]. IPCC, Geneva, Switzerland, 151 pp., 2014.

Jenkins, D. P., Patidar, S., Banfill, P., and Gibson, G.: Developing a probabilistic tool for assessing the risk of overheating in buildings for future climates, Renew. Energ., 61, 7-11, doi:10.1016/j.renene.2012.04.035, 2014.

Jones, R. N.: Managing uncertainty in climate change projections: issues for impact assessment, Climatic Change, 45, 403-419, doi:10.1023/A:1005551626280, 2000.

Jones, P. D., Kilsby, C. G., Harpham, C., Glenis, V., and Burton, A.: UK Climate Projections science report: Projections of future daily climate for the UK from the Weather Generator, University of Newcastle, UK, 2009.

Kay, A. L. and Jones, D. A.: Transient changes in flood frequency and timing in Britain under potential projections of climate change, Int. J. Climatol., 32, 489-502, doi:10.1002/joc.2288, 2012.

Kilsby, C. G., Jones, P. D., Burton, A., Ford, A. C., Fowler, H. J., Harpham, C., James, P., Smith, A., and Wilby, R. L.: A daily weather generator for use in climate change studies, Environ. Modell. Softw., 22, 1705-1719, doi:10.1016/j.envsoft.2007.02.005, 2007.

Lee, S. E. and Levermore, G.: Simulating urban heat island effects with climate change on a Manchester house, Build. Serv. Eng. Res. T., 34, 203-221, doi:10.1177/0143624412439485, 2013.
Lempert, R. J. and Groves, D. G.: Identifying and evaluating robust adaptive policy responses to climate change for water management agencies in the American west, Technol. Forecast. Soc., 77, 960-974, doi:10.1016/j.techfore.2010.04.007, 2010.

Lopez, A., Fung, F., New, M., Watts, G., Weston, A., and Wilby, R. L.: From climate model ensembles to climate change impacts and adaptation: A case study of water resource management in the southwest of England, Water Resour. Res., 45, W08419, doi:10.1029/2008WR007499, 2009.

Manning, L. J., Hall, J. W., Fowler, H. J., Kilsby, C. G., and Tebaldi, C.: Using probabilistic climate change information from a multimodel ensemble for water resources assessment, Water Resour. Res., 45, W11411, doi:10.1029/2007WR006674, 2009.

Marsh, T.: The 2004-2006 drought in southern Britain, Weather, 62, 191-196, 2007.

Matrosov, E. S., Woods, A. M., and Harou, J.: Robust Decision Making and Info-Gap Decision Theory for water resources system planning, J. Hydrol., 494, 43-58, doi:10.1016/j.jhydrol.2013.03.006, 2013.

McDonald, A. T.: Water demand and water needs in the UK [Chapter 2], Royal Society of Chemistry Report on Water Management, London, 2007.

Murphy, J. M., Sexton, D. M. H., Jenkins, G. J., Boorman, P. M., Booth, B. B. B., Brown, C. C., Clark, R. T., Collins, M., Harris, G. R., Kendon, E. J., Betts, R. A., Brown, S. J., Howard, T. P., Humphrey, K. A., McCarthy, M. P., McDonald, R. E., Stephens, A., Wallace, C., Warren, R., Wilby, R., and Wood, R. A.: UK Climate Projections Science Report: Climate change projections, Met Office Hadley Centre, Exeter, 2009.

New, M., Lopez, A., Dessai, S., and Wilby, R.: Challenges in using probabilistic climate change information for impact assessments: An example from the water sector, Philos. T. R. Soc. A, 365, 2117-2131, doi:10.1098/rsta.2007.2080, 2007.

Oxford Scientific Software Ltd:: A guide to AQUATOR, Oxford Scientific Software Ltd., 2004.

Parker, J. M. and Wilby, R. L.: Quantifying household water demand: a review of theory and practice in the UK, Water Resour. Manag., 27, 9581-1011, doi:10.1007/s11269-012-0190-2, 2013.

Patidar, S., Jenkins, D. P., Banfill, P., and Gibson, G.: Simple statistical model for complex probabilistic climate projections: overheating risk and extreme events, Renew. Energ., 61, 23-28, doi:10.1016/j.renene.2012.04.027, 2014.

Paton, F. L., Maier, H. R., and Dandy, G. C.: Including adaptation and mitigation responses to climate change in a multiobjective evolutionary algorithm framework for urban water supply systems incorporating GHG emissions, Water Resour. Res., 50, 6285-6304, doi:10.1002/2013WR015195, 2014.

Perry, M. and Hollis, D.: The development of a new set of long-term climate averages for the UK, Int. J. Climatol., 25, 1023-1039, doi:10.1002/joc.1160, 2005a.

Perry, M. and Hollis, D.: The generation of monthly gridded datasets for a range of climatic variables over the UK, Int. J. Climatol., 25, 1041-1054, doi:10.1002/joc.1161, 2005 b.

Rahiz, M. and New, M.: Does a rainfall-based drought index simulate hydrological droughts?, Int. J. Climatol., 34, 2853-2871, doi:10.1002/joc.3879, 2013.

Steinschneider, S., McCrary, R., Wi, S., Mulligan, K., Mearns, L., and Brown, C.: Expanded Decision-Scaling Framework to Select Robust Long-Term Water-System Plans under Hydroclimatic 
Uncertainties, Journal Water Res. Pl.-ASCE, 141, 04015023, doi:10.1061/(ASCE)WR.1943-5452.0000536, 2015.

Thames Water: Final Water Resources Management Plan 20152040, Thames Water Ltd., available at: http://www.thameswater. co.uk/tw/common/downloads/wrmp/WRMP14_Section_1.pdf (last access: 18 December 2014), 2014.

Thompson, J. R.: Modelling the impacts of climate change on upland catchments in southwest Scotland using MIKE SHE and the UKCP09 probabilistic projections, Hydrol. Res., 43, 507-530, doi:10.2166/nh.2012.105, 2012.

Vidal, J. P. and Wade, S.: A multimodel assessment of future climatological droughts in the United Kingdom, Int. J. Climatol., 29, 2056-2071, doi:10.1002/joc.1843, 2009.

Walsh, C. L., Dawson, R. J., Hall, J. W., Barr, S. L., Batty, M., Bristow, A. L., Carney S., Dagoumas, A., Ford, A. C., Harpham, C., Tight, M. R., Watters, H., and Zanni, A.: Assessment of climate change mitigation \& adaptation in cities, Urban Design and Planning, 164, 75-84, doi:10.1680/udap.2011.164.2.75, 2011.

Warren, A. J. and Holman, I. P.: Evaluating the effects of climate change on the water resources for the city of Birmingham, UK, Water Environ. J., 26, 361-370, doi:10.1111/j.17476593.2011.00296.x, 2012.

Whateley, S., Steinschneider, S., and Brown, C.: A climate change range based method for estimating robustness for water resources supply, Water Resour. Res., 50, 8944-8961, 2014.
Whitehead, P. G., Wilby, R. L., Butterfield, D., and Wade, A. J.: Impacts of climate change on in-stream nitrogen in a lowland chalk stream: An appraisal of adaptation strategies, Sci. Total Environ., 365, 260-273, doi:10.1016/j.scitotenv.2006.02.040, 2006.

Wilby, R. L.: Uncertainty in water resource model parameters used for climate change impact assessment, Hydrol. Process., 19, 3201-3219, doi:10.1002/hyp.5819, 2005.

Wilby, R. L. and Harris, I.: A framework for assessing uncertainties in climate change impacts: Low-flow scenarios for the River Thames, UK, Water Resour. Res., 42, W02419, doi:10.1029/2005WR004065, 2006.

Wilby, R. L., Greenfield, B., and Glenny, C.: A coupled synoptic hydrological model for climate change impact assessment, J. Hydrol., 153, 265-290, doi:10.1016/0022-1694(94)90195-3, 1994.

Wilby, R. L., Charles, S. P., Zorita, E., Timbal, B., Whetton, P., and Mearns, L. O.: Guidelines for Use of Climate Scenarios Developed from Statistical Downscaling Methods, IPCC Task Group on Scenarios for Climate Impact Assessment (TGCIA), Geneva, Switzerland, available at: http://www.narccap.ucar.edu/ doc/tgica-guidance-2004.pdf (last access: 5 October 2014), 2004.

Zeff, H. B., Kasprzyk, J. R., Herman, J. D., Reed, P. M., and Characklis, G. W.: Navigating financial and supply reliability tradeoffs in regional drought management portfolios, Water Resour. Res., 50, 4906-4923, 2014. 